University of South Carolina

Scholar Commons

$10-5-2000$

\title{
Preparation of Mesoporous Yttria-Stabilized Zirconia (YSZ) and YSZ-NiO Using a Triblock Copolymer as Surfactant
}

\author{
Fanglin Chen \\ University of South Carolina - Columbia, fchen@sc.edu \\ Meilin Liu \\ Georgia Institute of Technology - Main Campus
}

Follow this and additional works at: https://scholarcommons.sc.edu/emec_facpub

Part of the Mechanical Engineering Commons

\section{Publication Info}

Journal of Materials Chemistry, Volume 10, Issue 11, 2000, pages 2603-2605.

(C) 2000 Journal of Materials Chemistry, Royal Society of Chemistry

Publisher's Version: http://dx.doi.org/10.1039/B006561G

DOI: 10.1039/B006561G

This Article is brought to you by the Mechanical Engineering, Department of at Scholar Commons. It has been accepted for inclusion in Faculty Publications by an authorized administrator of Scholar Commons. For more information, please contact digres@mailbox.sc.edu. 


\section{Preparation of mesoporous yttria-stabilized zirconia (YSZ) and YSZ-NiO using a triblock copolymer as surfactant}

\section{Fanglin Chen and Meilin Liu*}

School of Materials Science and Engineering, Georgia Institute of Technology, Atlanta, GA, 30332-0245,USA. E-mail: meilin.liu@mse.gatech.edu

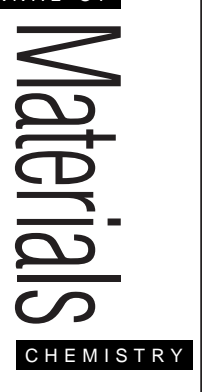

Received 10th August 2000, Accepted 29th August 2000
First published as an Advance Article on the web 5th October 2000

Mesoporous yttria-stabilized zirconia (YSZ) and YSZ-NiO have been prepared for the first time using Pluronic P103 as a structure-directing agent and inorganic chlorides as precursors in a nonaqueous medium. After being fired at $500{ }^{\circ} \mathrm{C}$ for $2 \mathrm{~h}$, mesostructured YSZ has a BET surface area of about $146 \mathrm{~m}^{2} \mathrm{~g}^{-1}$, with an average pore size of $3.8 \mathrm{~nm}$, while mesostructured $\mathrm{YSZ}-\mathrm{NiO}$ has a BET surface area of about $108 \mathrm{~m}^{2} \mathrm{~g}^{-1}$, with an average pore size of $4.5 \mathrm{~nm}$.

\section{Introduction}

The successful preparation of the M41S family of mesoporous molecular sieves using a supramolecular templating approach has stimulated an explosion in research on the preparation of highly ordered mesoporous or nanostructured materials through templating techniques. ${ }^{1-3}$ The ordering in these materials is a consequence of a self-assembly process that occurs spontaneously in an aqueous solution containing organic surfactants (anionic, cathodic, or neutral) and inorganic (oligo-) cations or anions. ${ }^{48}$ The use of surfactant species to organize mesoporous silica has been widely explored. However, extension of the surfactant templating process to the formation of non-silica mesoporous oxides, especially complex transition metal oxides, has been much less successful, although these compounds display very interesting functionality for electrochemical and catalytic applications such as catalysis, separation, batteries and fuel cells.

Recently, it has been discovered that non-ionic alkyl poly(ethylene oxide) (PEO) surfactants and amphiphilic block copolymers (such as Pluronic surfactants) can be used to organize, not only mesostructured silica, but also mesostructured non-silica oxides. ${ }^{9-13}$ This discovery represents a significant advance in the area of synthesis of mesoporous complex metal oxides. Pluronic surfactants are PEO-poly(propylene oxide) (PPO) triblock copolymers with the formula $(\mathrm{PEO})_{n}(\mathrm{PPO})_{m}(\mathrm{PEO})_{n}$, in which the PPO linkages act as the hydrophobic segments while the PEO linkages act as the hydrophilic segments. Since the chain length of the triblock copolymers can be tuned to balance the hydrophobic and hydrophilic portions in the ampliphilic surfactants, pore size and pore size distribution can be readily tailored using such surfactants. Using Pluronic surfactants as structure-directing agents and inorganic chlorides as precursors in non-aqueous solutions, Yang et al. ${ }^{12,13}$ have recently prepared a series of thermally stable, ordered, large-pore mesoporous metal oxides and composites. In this article, we report our findings using Pluronic P103 surfactant as structure-directing agents for the preparation of mesoporous yttria-stabilized zirconia (YSZ) and YSZ-NiO composite for electrochemical applications such as in solid oxide fuel cells (SOFCs). ${ }^{14}$

\section{Experimental}

The starting materials for preparation of mesoporous YSZ and YSZ-NiO are zirconium dichloride oxide, yttrium chloride, nickel chloride, and Pluronic P103. In a typical synthesis, $1 \mathrm{~g}$ Pluronic P103 was dissolved in $15 \mathrm{ml}$ ethanol. To this solution, $0.01 \mathrm{~mol}$ of the appropriate inorganic chloride precursors were added and stirred until a clear solution was obtained. The resulting sol solution was gelled in an open porcelain dish for 3 days at $40^{\circ} \mathrm{C}$ in an oven with saturated water vapor. The resulting gel was then dried in a vacuum oven. The dried gel was pulverized and calcined in air at 500 to $800{ }^{\circ} \mathrm{C}$ for $2 \mathrm{~h}$ with a heating and cooling rate of $2{ }^{\circ} \mathrm{C} \mathrm{min}-1$. Low-angle and wideangle X-ray powder diffraction patterns were obtained on a Scintag X1 diffractometer using $\mathrm{Cu}-\mathrm{K} \alpha$ radiation. A Rheometric Scientific STA 1500 instrument was used for simultaneous thermogravimetry (TG) and differential scanning calorimetry (DSC) with a heating rate of $2{ }^{\circ} \mathrm{C} \mathrm{min}^{-1}$. Transmission electron microscopy (TEM) studies were performed on a Hitachi HF2000 electron microscope operating at $200 \mathrm{keV}$. The samples were prepared by directly dispersing fine powders of the products onto holey carbon nickel grids. The

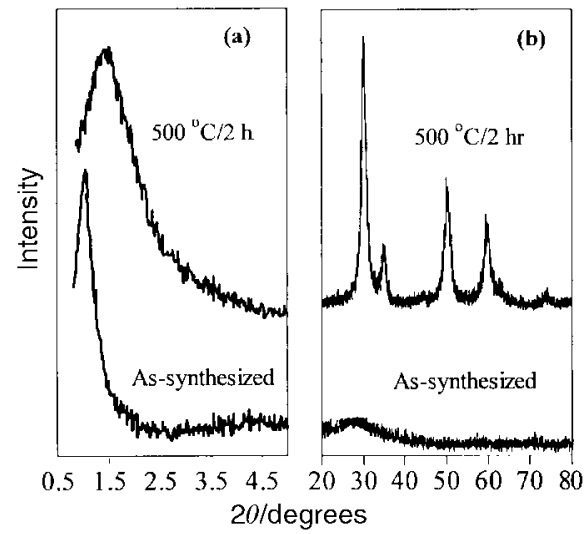

Fig. 1 (a) Low-angle and (b) wide-angle X-ray diffraction (XRD) patterns of as-synthesized $\left(40{ }^{\circ} \mathrm{C} / 3\right.$ days $)$ and as-calcined $\left(500^{\circ} \mathrm{C} / 2 \mathrm{~h}\right)$ mesoporous YSZ.

J. Mater. Chem., 2000, 10, 2603-2605

This journal is $\mathbb{C}$ The Royal Society of Chemistry 2000 
nitrogen adsorption and desorption isotherms at $77 \mathrm{~K}$ were measured using a Coulter SA 3100 surface analyzer after degassing of the samples at $200^{\circ} \mathrm{C}$ for $24 \mathrm{~h}$ with dry nitrogen.

\section{Results and discussion}

\subsection{Preparation of mesoporous YSZ}

Fig. 1 shows several typical XRD patterns for mesostructured YSZ prepared using Pluronic P103 as the structure-directing agent. In the low angle range, only one peak was observed for the as-synthesized YSZ inorganic/polymer mesostructure, corresponding to $d=84 \AA$, indicating that the surfactant molecules were organized into a hexagonal structure after being aged at $40{ }^{\circ} \mathrm{C}$ for 3 days. When the as-synthesized YSZ was calcined at $500{ }^{\circ} \mathrm{C}$ for $2 \mathrm{~h}$, the small angle diffraction peak shifted to a higher angle, corresponding to $d=59 \AA$, suggesting that the mesoporous superstructure was preserved after the surfactant was removed by calcination. However, the pores contracted from 84 to $59 \AA$, as evidenced from the shift of the XRD peak. When the calcination temperature was increased to $600{ }^{\circ} \mathrm{C}$, the low angle XRD peak disappeared, implying that the ordered mesostructure had been destroyed. The XRD patterns shown in Fig. 1(b) indicate that the as-synthesized YSZ is amorphous while the calcined YSZ is crystalline (Fluorite structure).

The TG and DSC curves obtained from an as-synthesized YSZ sample (inorganic/polymer mesostructure) are shown in Fig. 2. The TG curve shows that most weight loss occurred below $490^{\circ} \mathrm{C}$, indicating that the block copolymer can be completely removed upon calcination in air at $500^{\circ} \mathrm{C}$ for $2 \mathrm{~h}$. The two exothermal events observed from the DSC curve correspond to the release of $\mathrm{H}_{2} \mathrm{O}, \mathrm{CO}$ and $\mathrm{CO}_{2}$ from the decomposition of the surfactant.

A representative TEM image of a YSZ sample calcined at $500{ }^{\circ} \mathrm{C}$ for $2 \mathrm{~h}$ is shown in Fig. 3. Mesostructures with shortrange hexagonal order can be seen and the pore size determined from the TEM micrographs is in good agreement with that determined from the XRD pattern. Thus, we have obtained mesoporous YSZ (without surfactant) stable up to $500^{\circ} \mathrm{C}$.

A typical nitrogen adsorption-desorption isotherm curve and the corresponding Barrett-Joyner-Halenda (BJH) pore size distribution curve for a YSZ sample calcined at $500^{\circ} \mathrm{C}$ for $2 \mathrm{~h}$ are shown in Fig. 4. The calculated Brunauer-EmmettTeller (BET) surface area is about $146 \mathrm{~m}^{2} \mathrm{~g}^{-1}$. The nitrogen isotherm curve has a well-defined step for the relative pressure $P / P_{0}$ ranging from 0.4 to 0.8 , characteristic of the filling of the framework-confined mesopores, ${ }^{15}$ confirming that the YSZ sample is still mesoporous after calcination at $500^{\circ} \mathrm{C}$ for $2 \mathrm{~h}$.

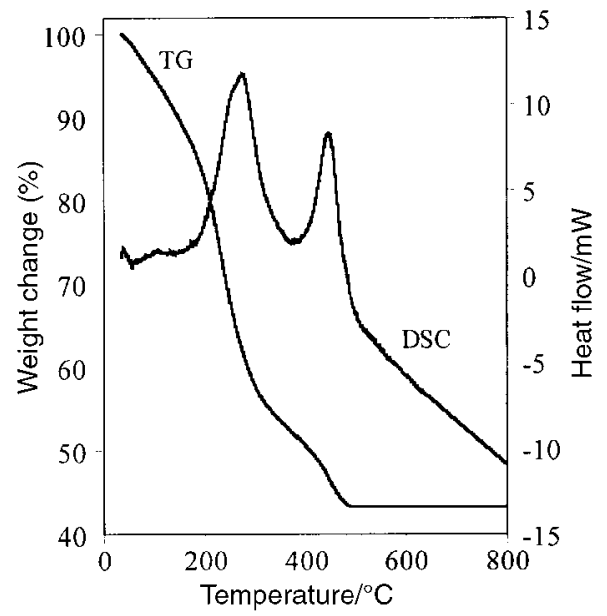

Fig. 2 Weight change and heat flow recorded for as-synthesized mesostructured YSZ. The heating rate was $2{ }^{\circ} \mathrm{C} \min ^{-1}$.

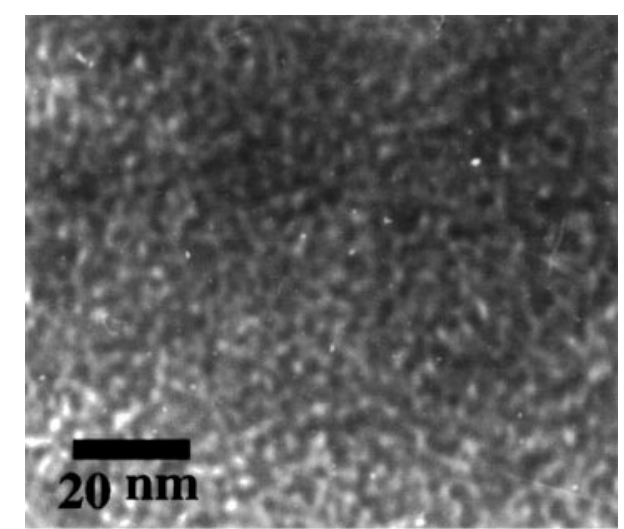

Fig. 3 A representative TEM micrograph of mesoporous YSZ calcined at $500{ }^{\circ} \mathrm{C}$ for $2 \mathrm{~h}$.

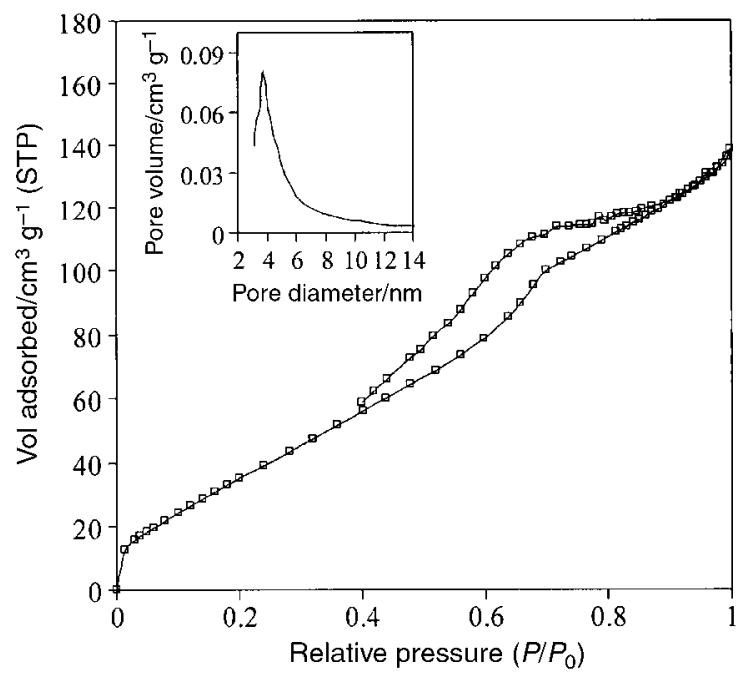

Fig. 4 Nitrogen adsorption-desorption isotherms for mesoporous YSZ calcined in air at $500{ }^{\circ} \mathrm{C}$ for $2 \mathrm{~h}$. The corresponding $\mathrm{BJH}$ pore size distribution is shown in the inset.

As shown in the inset in Fig. 4, the average pore size in the YSZ sample is about $3.8 \mathrm{~nm}$.

\subsection{Preparation of mesoporous YSZ-NiO}

Fig. 5 shows representative XRD patterns for mesostructured YSZ-NiO composite prepared using Pluronic P103 as the structure-directing agent. In the low angle range, one diffraction peak (corresponding to $d=79 \AA$ ) was observed for the as-

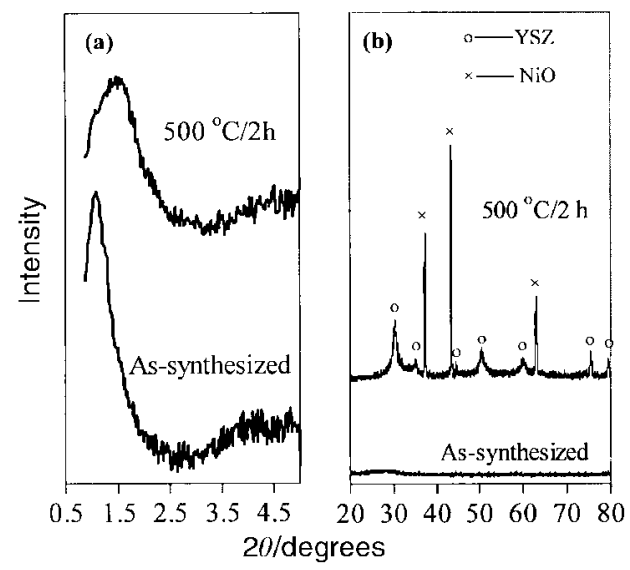

Fig. 5 (a) Low-angle and (b) wide-angle X-ray diffraction (XRD) patterns of as-synthesized $\left(40^{\circ} \mathrm{C} / 3 \mathrm{~d}\right)$ and as-calcined $\left(500{ }^{\circ} \mathrm{C} / 2 \mathrm{~h}\right)$ mesoporous YSZ-NiO. 


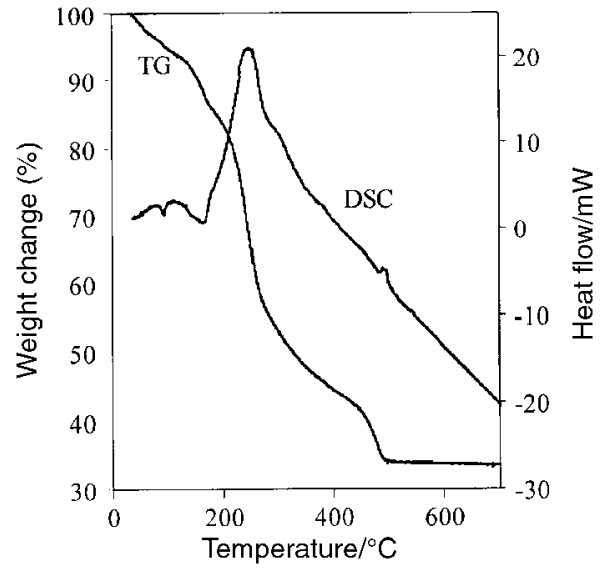

Fig. 6 Weight change and heat flow recorded for as-synthesized mesostructured $\mathrm{YSZ}-\mathrm{NiO}$ composite. The heating rate was $2^{\circ} \mathrm{C} \mathrm{min}{ }^{-1}$.

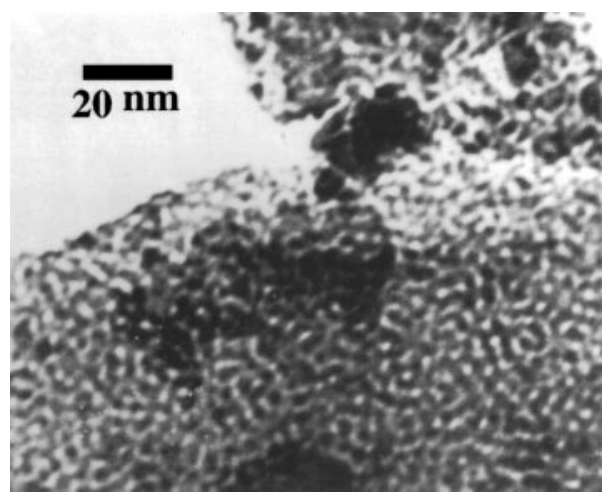

Fig. 7 A representative TEM micrograph of mesoporous YSZ-NiO composite calcined in air at $500^{\circ} \mathrm{C}$ for $2 \mathrm{~h}$.

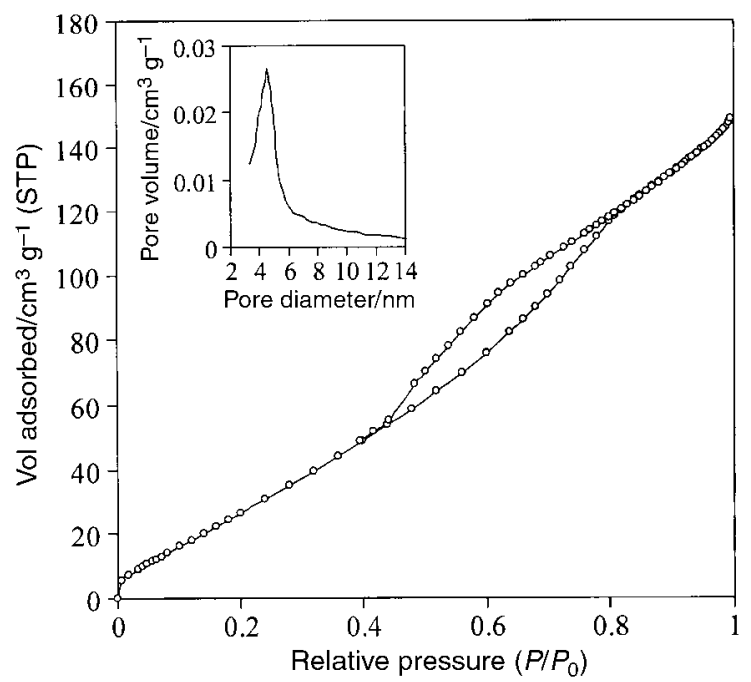

Fig. 8 Nitrogen adsorption-desorption isotherms for mesoporous YSZ-NiO composite calcined in air at $500{ }^{\circ} \mathrm{C}$ for $2 \mathrm{~h}$. The corresponding $\mathrm{BJH}$ pore size distribution is shown in the inset.

synthesized YSZ-NiO inorganic/polymer mesostructure. After being held at $500{ }^{\circ} \mathrm{C}$ for $2 \mathrm{~h}$, the diffraction peak for the ascalcined sample shifted to a higher angle, corresponding to $d=56 \AA$. However, when the calcination temperature was increased to $600^{\circ} \mathrm{C}$, the low angle XRD peak disappeared, indicating that the ordered mesostructure of YSZ-NiO became disordered. The XRD patterns shown in Fig. 5(b) indicate that the as-synthesized YSZ-NiO is amorphous while the calcined YSZ-NiO is crystalline.

TG and DSC curves for an as-synthesized YSZ-NiO sample are shown in Fig. 6. The TG curve indicates that all weight loss occurred below $500^{\circ} \mathrm{C}$, suggesting that the block copolymer is completely removed upon calcination in air at $500{ }^{\circ} \mathrm{C}$ for $2 \mathrm{~h}$.

A TEM image of YSZ-NiO composite calcined at $500^{\circ} \mathrm{C}$ for $2 \mathrm{~h}$ is shown in Fig. 7. Mesostructures with short-range hexagonal order can be seen and the pore sizes determined from the TEM micrographs are in good agreement with those obtained from the XRD patterns. Consequently, we have obtained mesoporous $\mathrm{YSZ}-\mathrm{NiO}$ stable up to $500^{\circ} \mathrm{C}$.

A representative $\mathrm{N}_{2}$ adsorption-desorption isotherm curve and the corresponding $\mathrm{BJH}$ pore size distribution curve for a YSZ-NiO sample calcined at $500{ }^{\circ} \mathrm{C}$ for $2 \mathrm{~h}$ are shown in Fig. 8. A hysteresis loop that resembles typical H1-type isotherms is observed for the mesoporous YSZ-NiO sample. ${ }^{16}$ The calculated BET surface area is about $108 \mathrm{~m}^{2} \mathrm{~g}^{-1}$. BJH analysis shows that the calcined hexagonal mesoporous YSZ-NiO exhibits mean pore sizes of $4.5 \mathrm{~nm}$.

\section{Summary}

Mesoporous YSZ and YSZ-NiO composite have been successfully prepared using Pluronic P103 as the structuredirecting agent and the corresponding metal chlorides as precursors in an alcoholic medium. The surfactant can be completely removed by firing the mesostructured inorganic/ polymer powders in air at $500{ }^{\circ} \mathrm{C}$ for $2 \mathrm{~h}$. Mesostructured YSZ and YSZ-NiO materials with crystalline walls stable up to $500{ }^{\circ} \mathrm{C}$ have been obtained.

\section{Acknowledgements}

The authors wish to gratefully acknowledge partial support of this project by National Science Foundation under award no. CTS-9819850, and by the Georgia Institute of Technology Molecular Design Institute, under prime contract N00014-951-1116 from the Office of Naval Research.

\section{References}

1 C. T. Kresge, M. E. Leonowicz, W. J. Roth, J. C. Vartuli and J. S. Beck, Nature, 1992, 359, 710 .

2 J. S. Beck, J. C. Vartuli, W. J. Roth, M. E. Leonowicz, C. T. Kresge, K. D. Schmitt, C. T.-W. Chu, D. H. Olson, E. W. Sheppard, S. B. McCullen, J. B. Higgins and J. L. Schlenker, J. Am. Chem. Soc., 1992, 114, 10834

3 R. Mokaya, W. Zhou and W. Jones, Chem. Commun., 1999, 51

4 A. Sayari, Chem. Mater., 1996, 8, 1840.

5 D. M. Antonelli and J. Y. Ying, Angew. Chem., Int. Ed. Engl., 1995, 34, 2014; D. M. Antonelli and J. Y. Ying, Chem. Mater. 1996, 8, 874; D. M. Antonelli, A. Nakahira and J. Y. Ying, Inorg. Chem., 1996, 35, 426.

6 Z. R. Tian, W. Tong, J. Y. Wang, N. G. Duan, V. V. Krishnan and S. L. Suib, Science, 1997, 276, 926.

7 F. Chen and M. Liu, Chem. Commun., 1999, 1829.

8 Q. Huo, D. I. Margolese, U. Ciesla, D. G. Demuth, P. Feng, T. E. Gier, P. Sieger, A. Firouzi, B. F. Chmelka, F. Schuth and G. D. Stucky, Chem. Mater., 1994, 6, 1176.

9 G. S. Atlard, J. C. Glyde and C. G. Goltner, Nature, 1995, 378, 366.

10 C. G. Goltner, S. Henke, M. C. Weissenberger and M. Antonietti, Angew. Chem., Int. Ed., 1998, 37, 613.

11 D. Zhao, J. Feng, Q. Huo, N. Melosh, G. Fredrickson, B. Chmelka and G. D. Stucky, Science, 1998, 279, 548.

12 P. Yang, D. Zhao, D. I. Margolese, B. F. Chemelka and G. D. Stucky, Nature, 1998, 396, 152

13 P. Yang, D. Zhao, D. I. Margolese, B. F. Chemelka and G. D. Stucky, Chem. Mater., 1999, 396, 2813.

14 M. Guillodo, P. Vernoux and J. Fouletier, Solid State Ionics, 2000 127, 99.

15 B. Cabrera, J. E. Haskouri, J. Alamo, A. Beltran, D. Beltran, S. Mendioroz, M. D. Marcos and P. Amoros, Adv. Mater., 1999, 11, 379.

16 S. J. Gregg and K. S. W. Sing, Adsorption, Surface Area and Porosity, 2nd edn., Academic Press, London, 1982. 